\title{
RACISMO, SAÚDE E COMUNIDADES REMANESCENTES DE QUILOMBOS: REFLEXÕES DA FISIOTERAPIA
}

\author{
Dennis Soares Leite ${ }^{1}$ \\ Ana Luíza Ferreira Martins ${ }^{2}$ \\ Juliana Figueiredo Ferreira ${ }^{3}$ \\ Keila de Nazaré Madureira Batista ${ }^{4}$ \\ Maria José Aviz do Rosário
}

Resumo: Os quilombos fazem parte de uma época triste da história do Brasil. A escravidão deixou profundas marcas no país. Nesse período surgem as comunidades remanescentes de quilombos, lutando por acesso e políticas inclusivas. O acesso em saúde no Brasil, é, ainda uma questão muito polêmica. As populações quilombolas reivindicam direito à saúde plena e integral. O trabalho tem como o objetivo: realizar uma revisão da literatura atual, com o intuito de apresentar aos profissionais de saúde uma reflexão sobre as questões pertinentes às populações quilombolas e suas dificuldades na defesa de seus direitos de acesso à atenção em saúde. O assunto "saúde de quilombolas" é extremamente novo e ainda há muito por debater e avançar neste caminho. A literatura demonstra que ainda existe uma grande disparidade na Atenção à Saúde no Brasil, e que é necessário o envolvimento social e profissional para alteração desta realidade. É fundamental que todas as profissões de saúde despertem para este grande desafio, e possam se unir em uma corrente inter, multi e transdisciplinar, aumentando a proximidade a importantes grupos de brasileiros que, por uma motivação triste de nosso passado, estiveram e ainda estão excluídos do processo atual de desenvolvimento. As políticas públicas em saúde devem buscar a equidade por meio da atenção inclusiva e grupos especiais, principalmente as comunidades quilombolas brasileiras.

Palavras-chave: Quilombolas. Saúde de quilombolas. Saúde da Família. Vulnerabilidade Social.

\footnotetext{
${ }^{1}$ Acadêmico de Fisioterapia, dennissoares7@gmail.com, Universidade Federal do Pará, campus Belém. Programa Conexões de Saberes/PROEX-UFPA.

${ }^{2}$ Acadêmica de Fisioterapia, Universidade Federal do Pará, campus Belém.

${ }^{3}$ Acadêmica de Fisioterapia, Universidade Federal do Pará, campus Belém

${ }^{4}$ Doutora em Doenças Tropicais, Professora da Universidade Federal do Pará, campus Belém.

${ }^{5}$ Doutora em Educação, Professora da Universidade Federal do Pará, campus Belém.
} 


\begin{abstract}
The quilombos are part of a sad time in the history of Brazil. Slavery has left deep marks in the country. In this period arise the remaining quilombo communities, fighting for access and inclusive policies. The health access in Brazil is still a very controversial issue. The Maroons claim the right to full and complete health. The work is the goal: to conduct a review of the current literature, in order to introduce health professionals to reflect on the issues relevant to the quilombo people and their difficulties in defending their rights of access to health care. The subject of "health quilombo" is very new and there is still much to discuss and advance in this way. The literature shows that there is still a wide disparity in Health Care in Brazil and the social and professional involvement to change this reality is necessary. It is essential that all health professions awaken to this great challenge, and can join in a current inter, multi and transdisciplinary, increasing proximity to major Brazilian groups, for a sad motivation of our past, they have been and still are excluded the current development process. The public health policies should seek equity through inclusive attention and special groups, especially the Brazilian Quilombo communities.
\end{abstract}

Keywords: Maroons. Health Maroons. Family Health. Social vulnerability.

\title{
INTRODUÇÃO/JUSTIFICATIVA
}

A cor da pele pode ser vista como manifestação biológica na figura humana, mas também pode se mascarar em expressão "racializada" da biologia, quando exposta a atitudes segregadoras dentro da sociedade. Os termos, raça e etnicidade são categorias sociais, mais do que biológica, referentes a grupos que têm em comum uma herança cultural. As desigualdades raciais, nas condições de saúde das populações, permanecem sendo um grande problema de saúde pública em vários países, como expressão de diferenças biológicas, disparidades sociais e discriminação étnica (LEAL, 2005). É preciso ampliar a discussão do direito a saúde, que é uma das premissas básicas do Sistema Único de Saúde (SUS), levando em conta que o acesso ao mesmo, passa ainda pelas condições sociais e econômicas da população e não apenas de sua condição étnica. 
Mas sem perdermos de vista que a universalidade do SUS, que seria o pleno acesso aos serviços públicos de saúde e de qualidade, para toda a população brasileira ainda não se efetivou na prática (SILVA, 2010). Para o Ministério da Saúde, a política de inclusão da população quilombola inicia-se, efetivamente, em 2004 com a Portaria n. ${ }^{0} 1.434$, de 14/7/2004, que criou um incentivo para a ampliação de equipes de estratégia da saúde para as comunidades quilombolas (OLIVEIRA, 2007)

\section{OBJETIVOS}

Realizar uma revisão da literatura atual, com o intuito de apresentar aos profissionais de saúde uma reflexão sobre as questões pertinentes às populações quilombolas e suas dificuldades na defesa de seus direitos de acesso à atenção em saúde.

\section{METODOLOGIA}

Para o desenvolvimento deste estudo sobre saúde e as populações quilombolas, foram realizadas buscas de literatura científica nas seguintes bases de dados online/portais de pesquisa: Pubmed/Medline, Scielo, LILACS e BIREME. Os descritores e expressões utilizados durante as buscas nas bases de dados foram: quilombolas, saúde de quilombolas, quilombos, desigualdade social, vulnerabilidade social, critérios raça/cor e saúde, atenção à saúde de quilombolas, quilombolas e saúde da família. Foram utilizados os artigos publicados nos últimos 10 anos, os quais correspondem aos anos de 2005 ao ano de 2015, de qualquer idioma, que apresentassem relevância relativa ao tema pesquisado.

\section{RESULTADOS}

A palavra "quilombo", que em sua etimologia bantu quer dizer acampamento guerreiro na floresta foi popularizada no Brasil pela administração colonial, em suas leis, relatórios, atos e decretos, para se referir às unidades de apoio mútuo criadas pelos rebeldes ao sistema escravista e às suas reações, organizações e lutas pelo fim da escravidão no País. Essa palavra teve também um significado especial para os libertos, em sua trajetória, conquista e liberdade, alcançando amplas dimensões e conteúdos. 
Pensar um quilombo pode levar, e constantemente leva, a um impulso quase inconsciente de imaginar um local habitado por negros que, em uma luta sangrenta, buscam a liberdade com a fuga, retirando-se do campo mais direto de batalha para continuarem em outras frentes de luta.

A casa grande e a senzala sempre foram espaços de organização e luta política. Fugir dos grilhões, que aprisionavam a uma situação de exploração máxima, foi, sem dúvida, uma forma de resistir ao sistema escravista e de alcançar a liberdade (LEAL, 2005). Dentro do contexto das chamadas populações tradicionais no Brasil, é um desafio conceituar aquilo que chamamos de população quilombola. Optamos por enquadrar este grupo étnico, como um grupo minoritário dentro da população negra, a exemplo da metodologia utilizada pelo Ministério da Saúde. Ainda podemos utilizar o conceito de comunidades remanescentes de quilombos do Governo Federal, que é utilizado pelos Ministérios e pelo Instituto Nacional de Colonização e Reforma Agrária, por meio da Instrução Normativa No 16, de 24 de março de 2004 que diz em seu artigo terceiro e quarto: "Consideram-se remanescentes das comunidades dos quilombos, os grupos étnico raciais, segundo critérios de auto atribuição, com trajetória histórica própria, dotados de relações territoriais específicas, com presunção de ancestralidade negra relacionada com a resistência à opressão histórica sofrida (CARDOSO, 2010).

O racismo surge na cena política brasileira, como doutrina científica, quando se avizinha à abolição da escravatura e, consequentemente, à igualdade política e formal entre todos os brasileiros, e mesmo entre estes e os africanos escravizados. Jamais pode ser visto apenas como reação à igualdade legal entre cidadãos formais, que se instalava com o fim da escravidão; foi também o modo como as elites intelectuais reagiam às desigualdades regionais crescentes que se avolumavam entre o Norte e o Sul do país, em decorrência da decadência do açúcar e da prosperidade trazida pelo café. Sempre que se trata de políticas especiais, um grande número de profissionais e pesquisadores busca debater se esta é necessária ou não, e atentam quase sempre para as questões de densidade populacional ou mesmo de dispersão territorial, e a indicação numérica do movimento quilombola (CALHEIROS, 2010).

A Secretaria Especial de Promoção da Igualdade Racial - Seppir (2010) estima a existência de 3.900 comunidades quilombolas em todo o país, acrescentando a esta 
estimativa a de que tais comunidades corresponderiam a 325 mil famílias, em uma razão de pouco mais de 80 famílias por comunidade. Este, ao menos do ponto de vista das manifestações públicas desta secretaria, é o horizonte populacional para o qual ela tem a função de articular as várias políticas públicas, dispersas por diferentes ministérios, fundações e secretarias. O número de comunidades registradas nas atuais políticas públicas, porém, estabelecido por meio do processo de certificação da Fundação Cultural Palmares, é de 1.739. Se aplicássemos a mesma razão de 80 famílias por comunidade usada na estimativa da Seppir, isso nos levaria a pouco menos que 145 mil famílias atendidas (MACHADO, 2010).

Quando se pensa nas comunidades quilombolas e seu acesso às políticas de saúde, não há como fechar os olhos ao grave problema das crianças. As comunidades, em sua maioria, caracterizam-se pelo forte vínculo com o meio ambiente. As famílias destas comunidades vivem da agricultura de subsistência, sendo a atividade econômica baseada na mão de obra familiar, para assegurar os produtos básicos para o consumo. As crianças aprendem a lidar na roça desde muito tenra idade. As condições sanitárias destas populações são insuficientes; a maior parte não possui água tratada e esgoto sanitário. Outra característica importante dessas comunidades é a ausência de serviços de saúde locais, fazendo com que, ao surgirem doenças, seus habitantes sejam obrigados a percorrer grandes distâncias em busca de ajuda. Todas estas questões acabam por aumentar o baixo índice de indicadores de saúde entre as crianças quilombolas (NARVAI, 2006).

A doença falciforme e a hipertensão arterial têm sido registradas com frequência nos dados coletados junto às comunidades quilombolas. Evidentemente que, a ausência de água tratada e a falta de condições sanitárias ideais, têm provocado o relato substancial de surtos de diarreia e doenças dermatológicas entre grande quantidade das populações remanescentes de quilombos. A grande problemática está em oferecer saúde integral combinada com a manutenção das crenças e tradições destes grupos. Cabe aqui ressaltar que, muitos povos quilombolas, ainda se utilizam de práticas alternativas e do uso de plantas consideradas por eles como medicinais. (OLIVEIRA, 2005). 


\section{CONCLUSÃO}

O assunto "saúde de quilombolas" é extremamente novo e ainda há muito por debater e avançar neste caminho. A literatura demonstra que ainda existe uma grande disparidade na Atenção à Saúde no Brasil, e que é necessário o envolvimento social e profissional para alteração desta realidade. É fundamental que todas as profissões de saúde despertem para este grande desafio, e possam se unir em uma corrente inter, multi e transdisciplinar, aumentando a proximidade a importantes grupos de brasileiros que, por uma motivação triste de nosso passado, estiveram e ainda estão excluídos do processo atual de desenvolvimento.

\section{REFERÊNCIAS}

CALHEIROS, F. P. Ethnic identity and power: quilombos in Brazilian public policy. Revista Katálysis 2010; 13(1): 133-139.

CARDOSO, L. F. C. Sobre imagens e quilombos: notas a respeito da construção da percepção acerca das comunidades quilombolas. Revista Estudo, Pesquisa e Educação. 2010; 12(1): 11-20.

LEAL, M. C. Desigualdades raciais, sociodemográficas e na assistência ao pré-natal e ao parto. Revista de Saúde Pública 2005; 39(01): 100-107.

MACHADO, C. V. O planejamento nacional da política de saúde no Brasil: estratégias e instrumentos nos anos 2000. Ciência \& Saúde Coletiva 2010; 15(5): 2367-2382.

NARVAI, P. C. Saúde bucal coletiva: caminhos da odontologia sanitária à bucalidade. Revista de Saúde Pública 2006; 40: 141-147.

OLIVEIRA, F. Saúde reprodutiva, etnicidade e políticas públicas do Brasil. Etnicidade na américa Latina: um debate sobre raça e direitos reprodutivos, Rio de Janeiro: FIOCRUZ; 2005, p.344.

OLIVEIRA, L. P. A educação para quilombolas: experiências de São Miguel dos Pretos em Restinga Seca (Rio Grande do Sul) e da comunidade Kalunga do Engenho II (Goiás). Caderno Cedes 2007; 27(72): 215-232.

SILVA, O. S. Quilombos do Sul do Brasil: movimento social emergente na sociedade contemporânea. Revista Identidade 2010;15(1):51-64. 